\title{
Correction: Results from ACROCOVID: an international survey on the care of acromegaly during the COVID-19 era
}

\section{Andrea Giustina $^{1} \cdot$ Ewen Legg $^{2} \cdot$ Bruno Mario Cesana $^{1} \cdot$ Stefano Frara ${ }^{1} \cdot$ Pietro Mortini $^{3} \cdot$ Maria Fleseriu $^{4}$}

Published online: 4 May 2021

(c) Springer Science+Business Media, LLC, part of Springer Nature 2021

Correction to: Endocrine

https://doi.org/10.1007/s12020-020-02565-1
The original version of the article unfortunately published Fig. 2 with the right hand side cut off.

This has been updated in this erratum.

The updated Fig. 2 is given below.
Fig. 2 Aspects of patient followup most affected by the COVID19 pandemic. Data indicate percentage of respondents reporting a negative effect in each specific area of patient management $(N=84)$

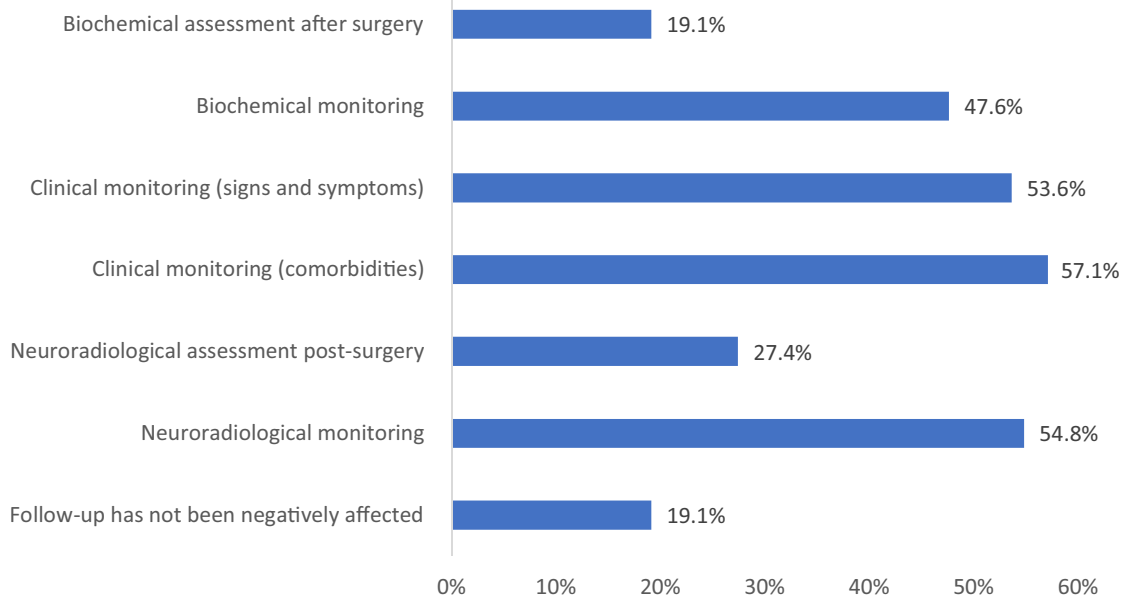

The original article can be found online at https://doi.org/10.1007/ s12020-020-02565-1.

Andrea Giustina

giustina.andrea@hsr.it

1 Institute of Endocrine and Metabolic Sciences, Università VitaSalute San Raffaele and IRCCS Ospedale San Raffaele, Milano, Italy

COR2ED, Bottmingen, Switzerland

3 Neurosurgery, Università Vita-Salute San Raffaele and IRCCS Ospedale San Raffaele, Milano, Italy

4 Pituitary Center, Oregon Health and Science University, Portland, OR, USA 